\title{
Strengthening climate-resilient development and transformation in Viet Nam
}

\author{
Arun Rana ${ }^{1}$ D $\cdot$ Qinhan Zhu ${ }^{2,4} \cdot$ Annette Detken $^{1} \cdot$ Karina Whalley $^{3} \cdot$ Christelle Castet $^{3}$
}

Received: 5 November 2020 / Accepted: 11 December 2021 /Published online: 8 January 2022

(c) The Author(s) 2022

\begin{abstract}
Climate change is presenting an ongoing and eminent threat to various regions, communities and infrastructure worldwide. In this study, the current and future climate impacts faced by Viet Nam due to Tropical Cyclones (TCs), specifically wind and surge, are evaluated, and different adaptation measures to manage this risk are appraised. The level of wind and storm surge risk was assessed focusing on three categories of assets: residential houses, agriculture, and people. The expected damage to these assets was then evaluated based on their exposure to the hazard under current and future climate scenarios. Physical adaptation measures such as mangroves, sea dykes, and gabions, and financial adaptation measures such as risk transfer via insurance were applied to the expected future risk and evaluated based on a socio-economic cost-benefit analysis. The output will give decisionmakers the ability to make more informed decisions, prioritize the most cost-effective adaptation measures and increase physical and financial resilience. The results indicated significant TC exposure in future climate scenarios due to economic development and climate change that almost doubles the current expected damage. Surge-related damage was found to be many times higher than wind damage, and houses had more exposure (value in total) than agriculture on a national scale. The physical adaptation measures are successful in significantly reducing the future wind and especially surge risk and would form a resilient strategy along with risk transfer for managing TC risks in the region.
\end{abstract}

Keywords Climate Resilience $\cdot$ Coastal Protection · Tropical Cyclones · Cost-benefit . Insurance $\cdot$ Nature-based solutions

Arun Rana

arunranain@gmail.com

1 Frankfurt School of Finance and Management gemeinnützige GmbH, Adickesallee 32-34, 60322 Frankfurt am Main, Germany

2 ETH Zürich, Chair of Weather and Climate Risks, Universitätstrasse 16, 8092 Zürich, Switzerland

3 AXA Climate, 36 Rue de Saint-Pétersbourg, 75008 Paris, France

4 International Institute for Applied Systems Analysis, Schlossplatz 1, A-2361 Laxenburg, Austria 


\section{Introduction}

Economic losses from natural catastrophes amounted to an estimated $\$ 232$ billion globally in 2019. There has been a steady increase in these figures over the last 20 years (Aon 2019). Among those perils, Tropical Cyclones (TCs) cause significant direct (economical) and indirect (social and demographic) damage; second only to flooding (Aon 2019; Takagi 2019). The combination of sea level rise and the economic development over coastal areas will also likely increase the impact of TCs and its associated storm surge on coastal communities and infrastructures (Geiger et al. 2016; Jongman et al. 2012), which are expected to surpass a cost of $\$ 1$ trillion on average per year by 2050 without any adaptation measures put in place (Hallegatte et al. 2013; Kulp and Strauss 2019). In addition to direct damages, these factors negatively influence long-term development such as economic output, mortality and displacement- The attribution to direct and indirect losses is particularly relevant for future projections of TC impacts given expected changes in population numbers and patterns (Jones and O'Neill 2016), economic growth, climate change (Knutson et al. 2019, 2020), and changes to vulnerabilities (Bakkensen and Mendelsohn 2016; Geiger et al. 2017; Lien 2019).

Peduzzi et al. (2012) projected that globally growth in coastal population and development will outpace any progress in adaptation measures against TC risk, based on current trends in losses. Thus, improving resilience and adaptation is increasingly important in the face of climate change. There is consensus in the scientific community that the intensity of TC wind speeds will likely increase. Consequently category four and five TCs will increase substantially in the coming decades (Holland and Bruyère 2014; Villarini and Vecchi 2013; Collins et al. 2019). This demands characterization of coastal and overland footprints (affected regions) of severe TC risk events.

Viet Nam is amongst the most vulnerable countries to TC risks given its 3,444 $\mathrm{km}$ of coastline, its location in the tropics of the Eastern Sea, and an economy highly dependent on agriculture in the vulnerable Mekong and Red River Delta regions. There are handful studies that study the impacts of TCs in the region (Thuy et al. 2015; Anh et al. 2019; Vu et al. 2018; Thuy 2019). Despite significant progress in quantifying the impact of climaterelated hazards in Viet Nam (Arouri et al. 2015; Kefi et al. 2018; Pham et al. 2018; Braese et al. 2020), there is a lack of research quantifying and comparing alternative adaptation measures and their cost-effectiveness on a national level, though available on global scale (Tamura et al. 2019). An assessment of the cost-effectiveness of potential adaptation measures supports national, provincial and community disaster management authorities in making informed decisions and prioritizing the most effective measures accordingly. Enhancing and rehabilitating natural coastal ecosystems are highly effective in reducing exposure to hydrometeorological hazards (Chausson et al. 2020). However, there is a lack of studies on the effectiveness of nature-based adaptation measures for coastal protection compared to engineered solutions and for low and lower middle-income countries. There is also scarce context-specific evidence to assess effectiveness in the local context. This paper adds to existing literature on the economic effectiveness of using nature-based solutions, grey infrastructure and risk transfer solutions to adapt to climate change.

In the current paper, the various forms of TC risk management in Viet Nam are presented based on principles of climate-based risk prevention, mitigation, and transfer (popularly also referred to as Economics of Climate Adaptation-ECA). Probabilistic climate risk analytics is shown to significantly support political decision-making. The methodology followed responds to three main concerns: 
1. What is the expected climate-related damage to assets (economic losses) and societies due to the identified climate risks?;

2. What are the options among behavioural, physical and financial adaptation measures, for reducing these damages?;

3. What is the cost-benefit of implementing such measures in the region?

The paper is divided into five sections: Introduction; Methodology in which the region and model setup is described; Results; Future Outlook and Conclusion. All economic monetary values are presented (and converted from other currencies) in USD with \$ symbol throughout the paper and are considered as current value.

\section{Methodology}

\subsection{Study Area and temporal coverage}

Viet Nam is the easternmost country on the Indochinese peninsula between $8-24^{\circ} \mathrm{N}$ and $102-110^{\circ} \mathrm{E}$ longitude and latitude, respectively. It covers a total area of $331,212 \mathrm{Km}^{2}$ with a 3,444-km-long coastline, and is particularly exposed to TC hazard, which poses an increasing threat to people, property and habitats. Considered one of the most vulnerable countries to disasters and climate change, Viet Nam has been hit by disasters causing more than 13,000 deaths and property damage in excess of $\$ 6.4$ billion over the past two decades (World Bank 2010). According to the Inform Risk Index it ranks among the top 10 countries for climate-related and natural hazard exposure (JRC 2020). We have evaluated the study results in the current and near future climate scenarios of 2050 with RCP 4.5 and RCP8.5 for future projections, further detailed in section 2.2.1 below. The near future scenario is choice is motivated by the time horizon that is common in the political process of international climate change negotiations and its implications on national climate change policies. With the time horizon of 2050 as long-term reference year for the national policy vision set in Viet Nam's Intended National Determined Contribution (INDC) submitted to the United Nations Framework Convention on Climate Change, 2050 that represents an essential reference date for Viet Nam's national climate change strategy and adaptation policy (UNFCCC 2011). The study intends to spark debate about, not only the risk and damages but also the adaptation measures that requires political discourse and will on the host country/municipality end and thus we intended to present the immediate threat at the current period and the increase it will have in the very near future scenario (2050). Additionally it is in common knowledge among climate community that the uncertainties in the climate scenarios are rather low (with more models agreeing with the GHG pathways) in the near future scenarios than at the end of century.

\subsection{Model Setup}

The TC wind and surge modules of probabilistic modelling platform CLIMADA (AznarSiguan and Bresch 2019; Bresch and Aznar-Siguan 2020) were used to simulate TCs in current and future scenarios in order to evaluate damage to assets. CLIMADA is used to estimate the expected current socio-economic damage as well as the incremental increase due to economic and population growth, as well as climate change over the next decades. 


\subsubsection{Hazard}

TCs are among the most harmful natural disasters worldwide causing on average \$29 billion in losses and affecting 22 million people each year (Guha-Sapir 2017). TCs are very prevalent in the Western Pacific basin and hit Viet Nam at least annually. A TC hazard dataset for wind and surge was created for 1980-2020. The wind hazard dataset is based on the global International Best Track Archive for Climate Stewardship (IBTrACS) (Knapp et al. 2010) which includes 269-recorded events making landfall in the domain. Figure 1 represents the mean wind intensity and storm surge within the Western Pacific basin for 100-year return period TC events making landfall in Viet Nam. Although the historical event set is 40 years, with resampling within CLIMADA, we can access the 100-year return period (Aznar-Siguan and Bresch 2019).

Holland 2008 elaborates the internal methodologies of CLIMADA for wind field and the surge hazard dataset (flood depth) is derived from wind intensity with a linear relationship that modifies the water level according to the local elevation and distance to the coastal line (Xu 2010). The hazard dataset is created on an irregular grid with: 30 arcsecond $\left(\sim 1 \mathrm{~km}^{2}\right)$ resolution along the coastline and going $50 \mathrm{~km}$ inland as well as over major population centres, which cover more than 95 percentile of the population; and a coarser resolution of 150 arcsecond for the rest of the country. To account for uncertainties and model sensitivity, each historic TC is resampled 100 times creating a large sample of stochastic events (a representative set of simulated events and process is detailed in AznarSiguan and Bresch 2019). For simulating surge, Climate Central's proprietary, high-accuracy Digital Elevation Model (DEM) known as CoastalDEM (Kulp and Strauss 2018) was

A - Wind intensity $(\mathrm{m} / \mathrm{s})$

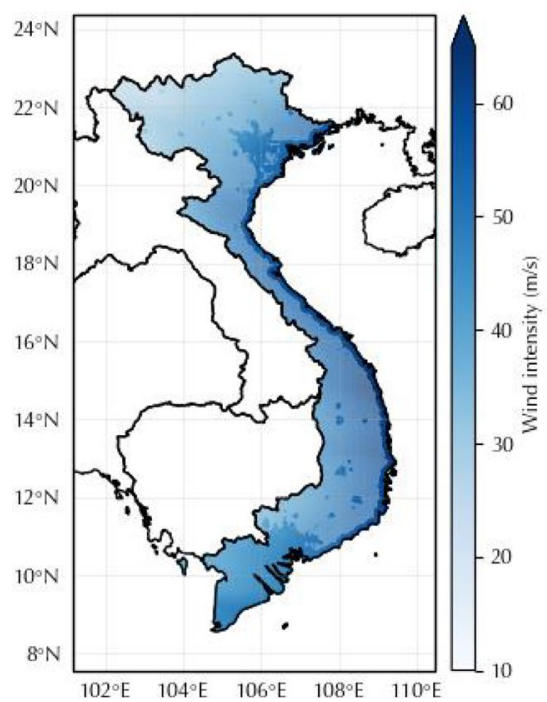

B - Storm surge level (m)

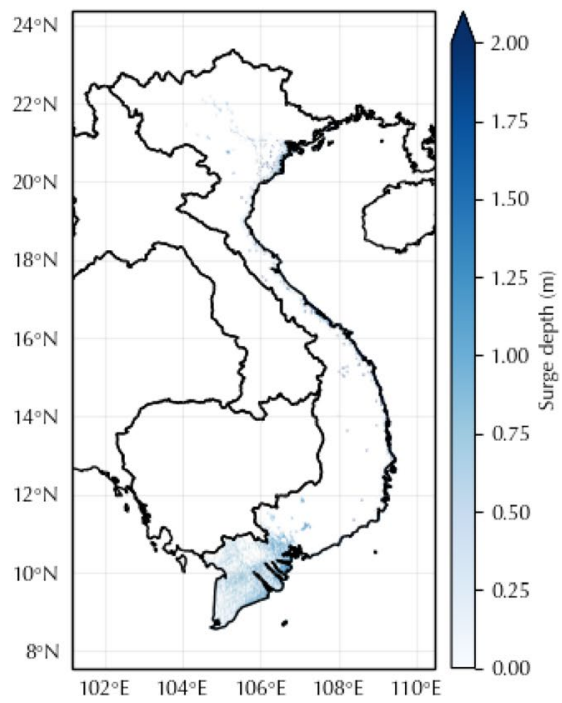

Fig. 1 Spatial distribution of wind hazard based on IBTrACS dataset over 1980-2020. Figure 1A and B presents wind intensity and storm surge level at the 1 in 100 year return period. The hazard dataset is used to simulate TC-related wind and surge damages in the historical period 
used at a resolution of 90 arcsecond. It reduces median errors in NASA's SRTM3 DEM to near zero and thus allows a better understanding of coastal risk. High accuracy DEMs from airborne lidar are unavailable.

The future hazard dataset is created with two future Representative Concentration Pathways (RCPs), RCP4.5 and RCP8.5, selected to represent the medium scenario and the worse-case scenario, respectively, in terms of climate change. While the current climate risk is simulated through CLIMADA's TC module using IBTrACS from 1980 to 2020, the future climate scenarios are also simulated through CLIMADA's TC module but based on assumptions from Knutson et al. 2015, which stipulate increased intensity and reduced frequency of TCs in the Eastern Pacific basin for both RCP4.5 and RCP8.5 scenarios by 2050. In order to perform a sensitivity analysis of the model, an alternative set of assumptions is used to simulate the future climate risk: increased intensity (Knutson et al. 2015; Lap 2019) and no change in frequency of TC compared to today (Table 1B). Choi et al. (2019) concluded that East Asian coastal areas will be affected by fewer TC landfalls but number of stronger TC landfalls may increase in the near future (2016-2030) compared to the present-day period (2002-2015). Thus this alternative scenario is a plausible future as the intensity and frequency of TC is expected to increase under thermodynamic climate change in most other sub-basins globally (Guan et al. 2018; Bruyère et al. 2019; Collins et al. 2019). Further sea level rise was accommodated within the future scenarios with 20 and $30 \mathrm{~cm}$ rise in North-western Pacific basin according to sea level project tool published by NASA.

\subsubsection{Exposure}

Physical risk is modelled as the direct economic impact of disasters and ideally represents the spatial distribution of physical asset stock. Aggregate estimates of asset values available through open-source data at national or sub-national level are used in this study for spatial distribution of asset values across the country and are re-distributed through CLIMADA using the LitPop distribution. Estimates of total asset values are derived from gross domestic product (GDP) given their strong correlation (Kuhn and Ríos-Rull 2016). Human presence and activity measured through linearly scaled night light intensity from satellite imagery is used for downscaling GDP based on geographical population data as detailed in Eberenz et al. 2020. This process is also known as LitPop distribution. The three assets in focus for this study, houses, agriculture and population, have been modelled with a universal resolution of 30 arcsecond.

To understand how climate change will impact future exposure, a holistic view is needed on the economic development paths, population growth, and value at risk in the coming decades. Table 1A presents the total aggregated exposure value, currently and in 2050 , for houses, agriculture and the population that are considered in the current study based on specific estimates.

For the future scenario, total population growth is assumed to be $13 \%$ from 2020 to 2050 (United Nations 2019). Average economic growth is assumed to be $2.5 \%$ annually until 2050. This rather conservative growth path is calculated in line with the target stated in the Viet Nam Government's latest national Socio-Economic Development Plan 2016-2020 (GOV 2016) to "become a modern-oriented industrialized country". In order for this to be achieved, Viet Nam would need to graduate from a lower middle-income to an upper middle-income country, according to World Bank classification (World Bank 2020b). This would imply that the national gross national income (GNI) per capita 


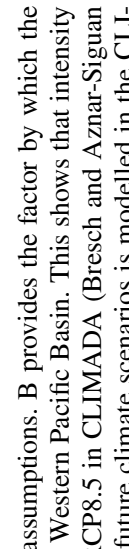

on

总票票

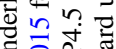

完实

일

或亮

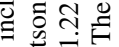

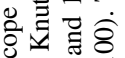

Din

풍ㅇㅇ

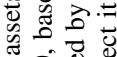

Ð

응

造品

政

过

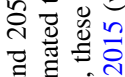

है

क्ष

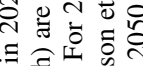

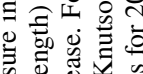

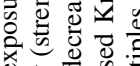

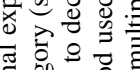

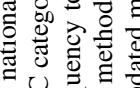

o

可

के

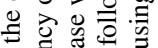

की

5 .

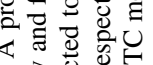

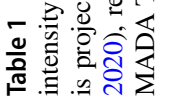

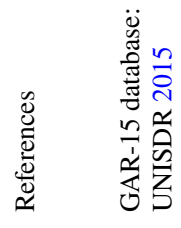

$\stackrel{ }{\circ}$

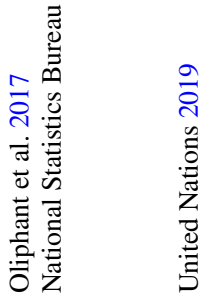

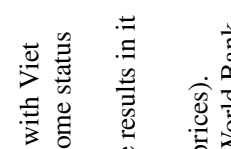

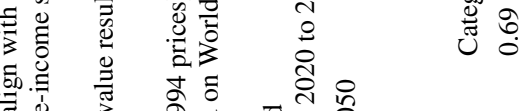

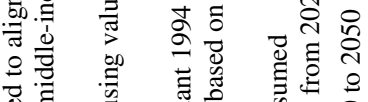

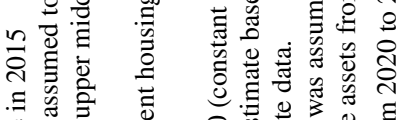

言言部

施

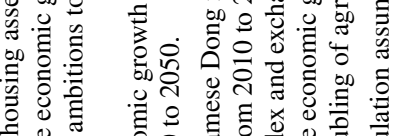

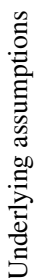

范

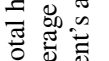

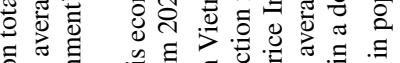

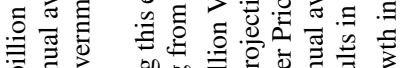

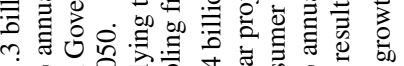

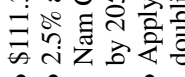

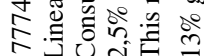

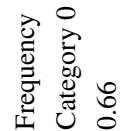

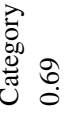

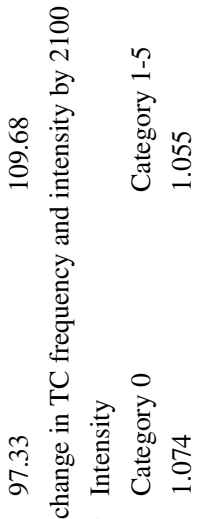

$\stackrel{\infty}{\infty}$

$\frac{1}{2}$

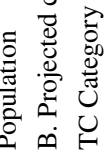


estimated at $\$ 2,540$ in 2019 (World Bank 2020a) would need to grow to at least $\$ 4,715$ by 2050 . Considering the $13 \%$ population growth, the economic growth necessary to achieve this would be $2.5 \%$ per year or a doubling of GDP or exposure by 2050 .

A conservative growth path was chosen to avoid exaggerating potential future economic losses. This growth assumption is also applied for the expected development of Vietnam's agricultural sector. The decision to follow the expected national growth rates for the agricultural sector is based on the findings of Vietnam Development Report (World Bank 2016) that outlines expected annual average growth rate of agricultural sector of 3.0-3.5\% until 2030. As the study analyses the impact of climate risks until 2050 , the conservative approach was also chosen with regard to the agricultural sector with the sectoral growth rate following the overall national GDP growth rate.

However, higher growth assumptions would lead to an increase in expected damages and thus even more significant benefits of the adaptation measures analysed. The discount rate, a representative assessment of today's value for future benefits/costs is herein accounted at 6\%. This provides transformed benefits of today's value and thus ensures comparison of real value of said benefit. The chosen rate accounts for the average inflation rate as measured by the Consumer Price Index (CPI) over the last 10 years (WDI 2020).

A. Houses - The Assessment Report on Disaster Risk Reduction (GAR 2015) (UNISDR 2015) provides baseline information for distribution of exposure. This dataset includes a statistical assessment of exposure of residential houses given fixed socioeconomic conditions. The baseline statistics from GAR-15 give an estimate of $\$ 111.3$ billion in total housing exposure in Viet Nam in 2015 which increases to $\$ 125.9$ billion in 2020 applying the $2.5 \%$ annual economic growth assumption (Table 1A). This was downscaled to 30 arcsecond (approximately $1 \mathrm{~km}$ resolution) with LitPop. For future exposure, housing stock is assumed to double by 2050 to $\$ 251.8$ billion (in line with $2.5 \%$ annual growth). This estimate was then downscaled with LitPop distribution. Figure 2 represents the current and future distribution of housing value exposure.
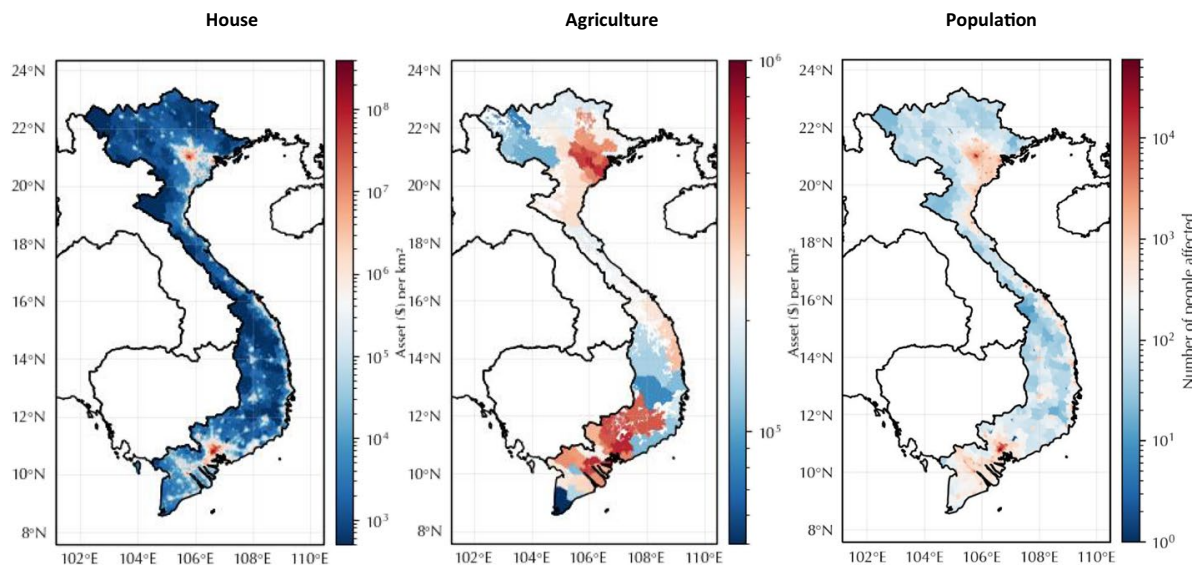

Fig. 2 Spatial distribution of exposure for the three assets considered in the study. The total aggregated exposure for the current year 2020 as outlined in Table 1 is distributed below at a resolution of $1 \mathrm{kmx} 1 \mathrm{~km}$ for all the assets 
B. Agriculture - NASA has two programmes, Making Earth System Data Records for Use in Research Environments (MEaSUREs) and Global Food Security-support Analysis Data (GFSAD), which provide cropland extent data over Southeast and Northeast Asia for the year 2015 at $30 \mathrm{~m}$ resolution (GFSAD30SEACE) (Oliphant et al. 2017). The GFSAD30SEACE data uses the pixel-based supervised classifiers, Random Forest (RF), to retrieve cropland extent from a combination of Landsat 8 Operational Land Imager (OLI), Landsat 7 Enhanced Thematic Mapper Plus (ETM+), and elevation derived from the Shuttle Radar Topography Mission (SRTM) Version 3 data products. The National Statistics Bureau provides agriculture production values for Viet Nam for 2010 (at provincial level and cumulative for all crop types) which were extrapolated through linear regression to reach $\$ 38.6$ million in 2020 and $\$ 77.2$ million in 2050 as shown in Table 1A (National Statistics Bureau 2010). To assess the current and future agriculture exposure in Viet Nam, the GFSAD30SEACE cropland extent dataset was converted to agriculture production using these values as shown in Fig. 2.

C. People - In this study, population is considered to be indirectly affected by natural disaster and is not considered a direct economic loss. Impacted population is the total number of people affected through displacement or loss of life due to TCs. To assess current population density, the total population estimate of 97.33 million people (United Nations 2019) in 2020 was distributed using LitPop method, but the power of night light intensity was set to 0 , meaning only the population distribution is used. The population was projected to 109.68 million people by 2050 using the $13 \%$ growth rate assumption, which was similarly distributed through LitPop. Figure $2 \mathrm{c}$ represents the current and future distribution of population density.

\subsubsection{Impact Functions}

An impact function parametrises the extent to which exposure will be affected by a specific hazard. In this study, six impact functions were created to assess the impact of wind and surge risk on the three exposure classes based on previous research and adjusted to the South East Asia context. For population, the impact functions were created by the authors in consultation with experts in the field (Fig. 3).

The effect of wind on houses is not observed until wind intensity reaches $30 \mathrm{~m} / \mathrm{s}$, rising to just $10 \%$ damage at $40 \mathrm{~m} / \mathrm{s}$ and rising linearly to $80 \%$ damage at $80 \mathrm{~m} / \mathrm{s}$. Damage to agriculture is negligible until wind speeds of $30 \mathrm{~m} / \mathrm{s}$ are reached, increasing to $98 \%$ damage at $120 \mathrm{~m} / \mathrm{s}$. People are not affected until wind speeds of $50 \mathrm{~m} / \mathrm{s}$ are reached after which it is estimated that $100 \%$ of the population is affected in the impacted zone (Geiger et al. 2018). For storm surge, houses are increasingly damaged up to $100 \%$ at a depth of $6 \mathrm{~m}$ following a power-shaped curve. Agriculture starts to be impacted from a water depth of $1 \mathrm{~m}$ and peaks at $100 \%$ damage at $5 \mathrm{~m}$ (sigmoidal shape), whereas all people are considered affected at $1 \mathrm{~m}$ water depth. It should be noted that the impact to agriculture does not include the damages from changes in soil salinity but is direct impacts due to flood height on the agriculture lands.

\subsubsection{Adaptation Measures}

Effective adaptation requires knowledge of risk drivers from an economic perspective including economic development and climate change (James et al. 2014). Nature-based or green infrastructure, which uses natural features of ecosystems for coastal protection, is a 


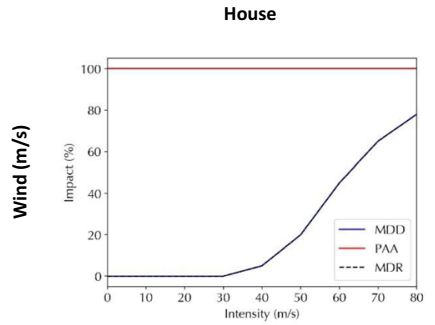

(Mason and Parackal, 2015)

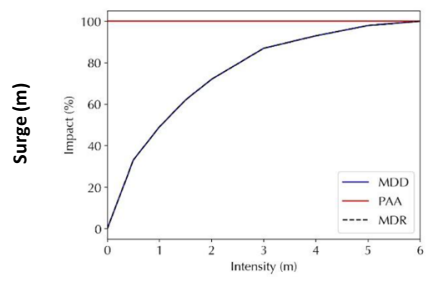

(Huizinga et. al. 2017)

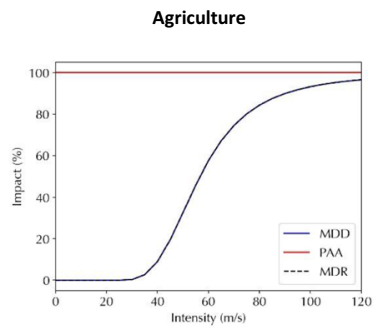

(Eberenz et. al. 2020)

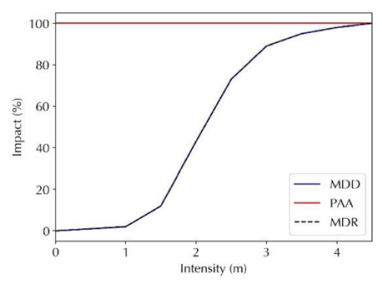

(Nhu et. al. 2017)

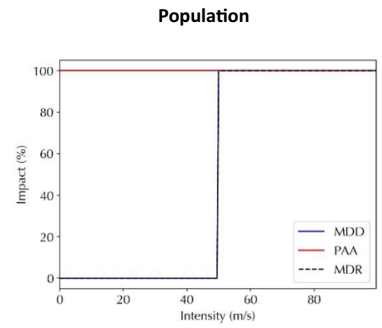

(Developed by Authors with inputs from Geiger et al. 2018)

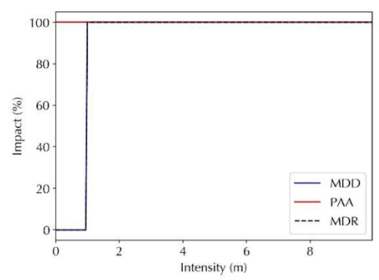

(Developed by Authors in consultation with experts in the field)

Fig. 3 Impact functions for TC-induced wind and surge damage were developed for the three asset categories based on impact functions collected through a literature review and then regionalized for Viet Nam. The reference used for each impact function is noted below each figure. (MDD-Mean Damage Degree; PAA - Percentage of Affected Asset; MDR_-Mean Damage Ratio)

cost-effective option to reduce storm surge, wind and wave impact (Temmerman et al. 2013). While there is strong support for the effectiveness of green infrastructure for coastal defense (Cheong et al. 2013; Spalding et al. 2014; Kumano et al. 2021), the optimum solution will likely be a diverse portfolio of adaptation measures including green (e.g. mangroves), grey (e.g. seawalls, and dykes) and risk transfer solutions (e.g. insurance) (Cooper and Pile 2014).

Given its significant exposure to natural disasters, the Government of Viet Nam (GOV) has made considerable efforts to address climate change over the last decade. In 2009, it developed a National Action Plan to Respond to Climate Change and defined implementation plans to coordinate climate actions at the national, provincial and community level (GOV 2009), introducing policies and developing implementation plans for high-risk areas to develop natural disaster risk reduction (prevention) and response preparedness plans. In 2011 the GOV adopted a comprehensive National Strategy on Climate Change (GOV 2011), which forms an essential basis for the Socio-Economic Development Plan (SEDP) 2016-2020 (GOV 2016), proposing climate change response, disaster prevention, resource management, and environmental protection to be mainstreamed into development planning at all governance levels. A Special Report on Managing the Risks of Extreme Events and Disasters to Advance Climate Change Adaptation (SREX) of the Intergovernmental Panel on Climate Change (IPCC) in 2015 (IMHEM and UNDP 2015) recommends different measures to improve management of climate and disaster risks in Viet Nam, stressing the benefits of ecosystem-based solutions and complementary climate risk transfer mechanisms, like climate risk insurance solutions.

Based on the adaptation measures defined in the National Strategy on Climate Change and the recommendations given in the SREX, three physical adaptation measures were 
selected for this study: building and rehabilitation of sea-dykes; construction of gabions to strengthen dykes; and plantation and rehabilitation of mangroves. Risk transfer was also applied to complement the adaptation measures. As climate and disaster risk management is advanced in Viet Nam, all of these physical measures have already been implemented in certain regions. There is however little public information on the current extent of these measures; their implementation standard/safety levels; nor their geographical location. Table 2 outlines the estimates used for each adaptation measure. Viet Nam has an extensive $2,659 \mathrm{~km}$ dyke system along its 3,444 km-long coast, focused mainly on the Red River and Mekong River Deltas, which protect coastal provinces against TCs and floods caused by storm surge. However, a recent World Bank study by Van Ledden et al. (2020), showed that safety standards of most coastal protection infrastructure are relatively low with more than $80 \%$ only built to sustain $10-30$-year events. Table 2 therefore includes both new and the rebuilding of existing structures. The benefits of these adaptation measures in reducing risk are incorporated into the modelling by decreasing the hazard directly in CLIMADA's TC module.

\section{Results}

Results are presented for the current and future impact of wind and surge risk incorporating climate change and economic growth assumptions for 2050; and a cost-benefit analysis of the three physical adaptation measures applied to the future scenarios.

\subsection{Impact - Current and future}

The economic direct impact of wind and surge hazards to houses and agriculture is measured in terms of Average Annual Loss (AAL) which is the cost of damage expected on average every year. The indirect impact on population is measured as the number of people impacted on average per year. Figure 4 presents the AAL and average number of people impacted per square kilometre due to wind and storm surge risk under current as well as RCP4.5 and RCP8.5 climate scenarios in 2050. The future scenarios assume increased intensity of TCs but no change in frequency relative to today. Results based on the alternative assumption of increased intensity and decreased frequency of TCs by 2050 are discussed below; however, visuals are only included in the supplementary material. The aggregate national-level figures for AAL and average number of people affected by wind and surge across all scenarios are compiled in Fig. 5 (also in tabular form in supplementary material Table 1).

\subsubsection{Impact due to wind}

Relative to storm surge, the impact of wind risk is much more widespread across the country for houses, agriculture and people. However, surge causes significantly more damage resulting in a higher AAL, especially for houses, and affects more people where it does occur (Fig. 5). Wind damage to houses in the current scenario causes an estimated AAL of $\$ 345$ million mainly concentrated on urban population centres and high exposure areas. In the future climate scenarios, the spatial distribution of wind damage is consistent with the current scenario but the magnitude is higher with total AAL of $\$ 445$ and 517 million for RCP4.5 and RCP8.5, respectively. Under 


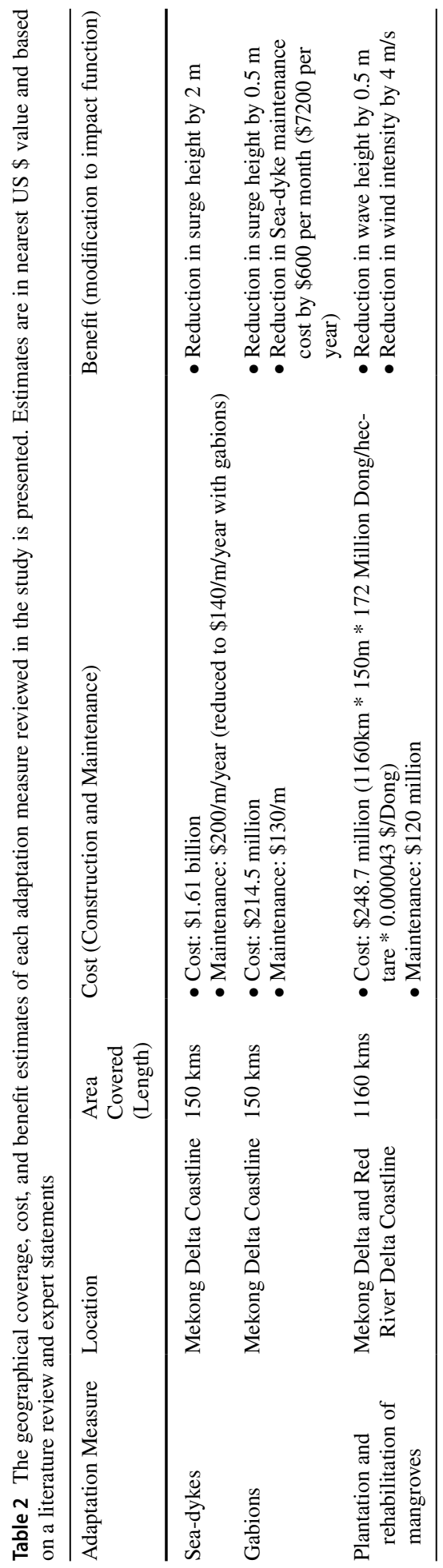




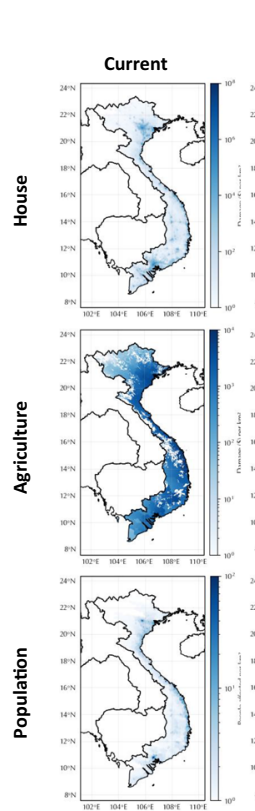

Wind

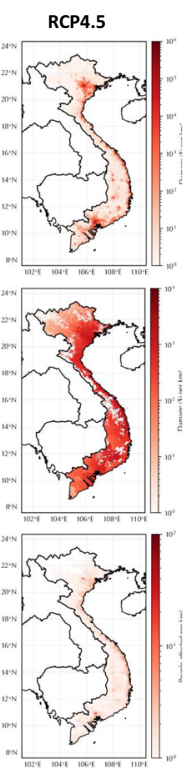

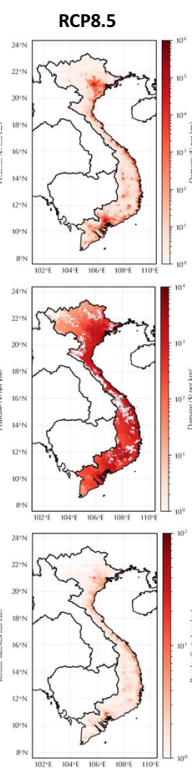

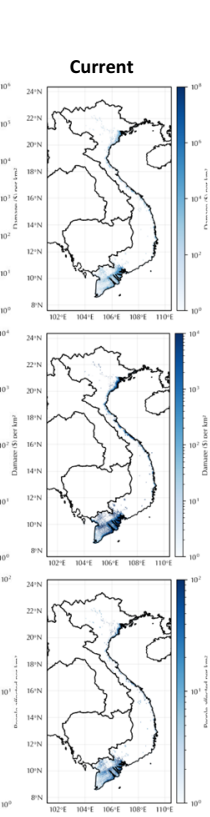

Surge

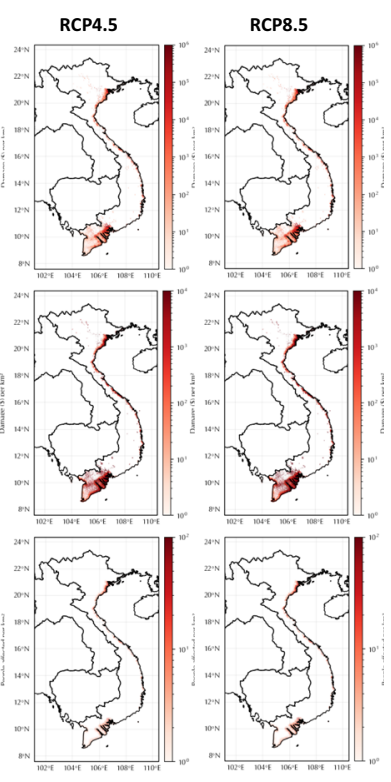

Fig. 4 Average annual loss/average annual number of people affected per square kilometre due to TCinduced wind and surge risk for each asset in the current 2020 scenario and additional damage (futurecurrent) in the future 2050 scenarios under RCP4.5 and RCP8.5. The future scenarios take into account economic growth and climate change with sea level rise and assume increased TC intensity and no change in $\mathrm{TC}$ frequency $(+\mathrm{I} / 0 \mathrm{~F})$ relative to current levels (conservative assumption)

the alternative assumption of increased intensity but decreased frequency of TCs in future, the AAL for wind damage to houses is projected to be $\$ 364$ and 363 million for RCP4.5 and RCP8.5, respectively, with identical spatial distribution.

Wind damage to agriculture is relatively uniform within each province as underlying agriculture exposure was based on provincial level data. In the current and future RCP4.5 and RCP8.5 climate scenarios, the AAL is estimated to reach $\$ 168,216$ and 250 million, respectively. However, under the alternative assumption of decreased TC frequency, AAL reduces to $\$ 177$ and 175 million for RCP4.5 and RCP8.5, respectively. Spatially wind damage to agriculture is higher in coastal regions than inland. Although RCP 8.5 is the higher greenhouse gas emission scenario, the assumption to significantly decrease TC frequency reduces the damage estimates below that of RCP4.5 although these estimates remain higher than the current scenario. The wide range in future scenario damage estimates under different TC frequency assumptions contributes to the sensitivity analysis of the model.

The average annual number of people currently affected by wind damage is estimated at 315,000 with the majority impacted along the coast and in major population centres. This rises to 443,000 and 539,000 people affected under RCP4.5 and RCP8.5, respectively, assuming no change in TC frequency and decreases to 374,000 and 398,000 people, respectively, under RCP4.5 and RCP8.5 assuming a decreased TC frequency. 


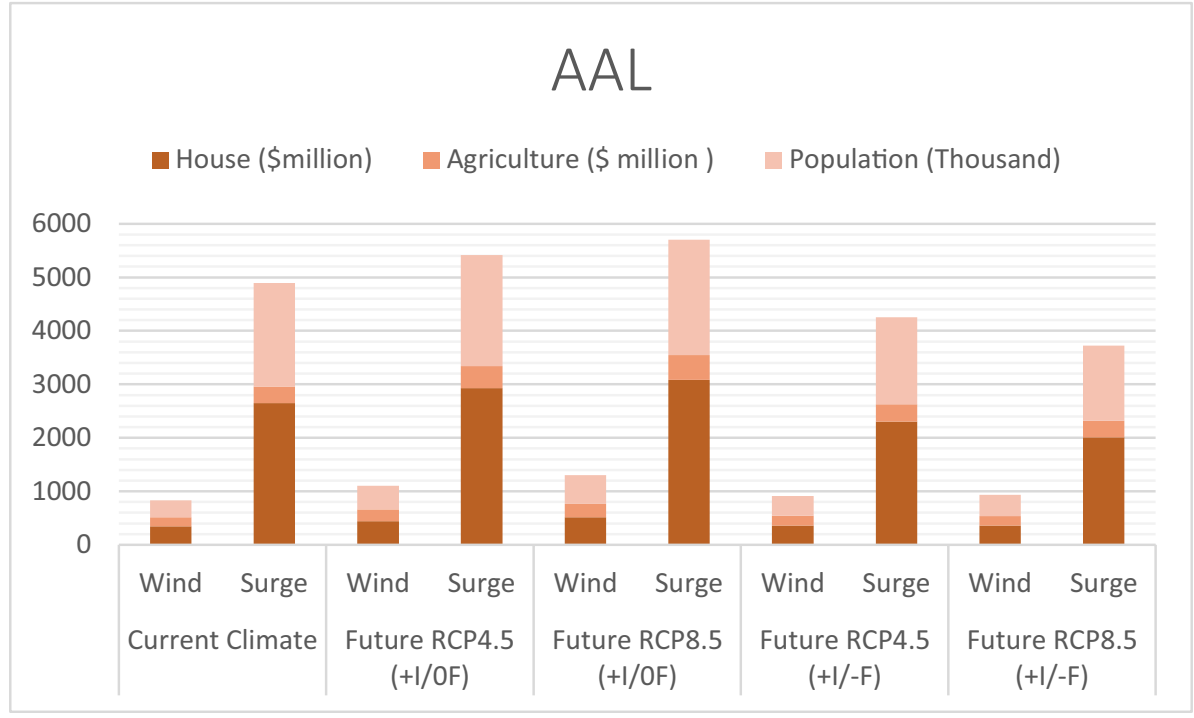

Fig. 5 The average annual loss (AAL) per asset. The AAL is calculated for the current and future scenarios. The latter take into account two climate change scenarios, RCP4.5 and RCP8.5, and economic growth. For each future scenario two sets of assumptions were used: increased intensity and decreased frequency of TCs $(+\mathrm{I} /-\mathrm{F})$ as per Knutson et al. 2015 and increased intensity and no change in frequency $(+\mathrm{I} / 0 \mathrm{~F})$ relative to current levels

\subsubsection{Impact due to surge}

Storm surge causes more damage than wind across all assets. The impact functions show that all assets are very sensitive to water depth with catastrophic damage in terms of cost and number of people affected caused at a relatively moderate water level. Surge currently causes an AAL of $\$ 2.65$ billion to houses, which increases to $\$ 2.93$ and 3.08 billion by 2050 for RCP4.5 and RCP8.5, respectively, assuming no change in TC frequency. Most of the significant damage occurs in coastal and low-lying areas such as the Mekong Delta. Inland flooding is not prominent except in the Mekong and Red River Delta that accounts for most surge damage to houses in the southern and northern territories, respectively. Assuming a decrease in TC frequency, the AAL for surge damage to houses decreases to $\$ 2.3$ and 2.01 billion for RCP4.5 and RCP8.5, respectively. It should be noted that under the alternative assumption of decreased TC frequency, TC intensity is still projected to increase. This implies that the proportion of strong and most destructive TCs is increasing even if the overall number of TCs is decreasing.

Unlike for houses, the impact of surge on agriculture is not very different to that of wind. This is due to the surge impact function for agriculture being flatter for a given water depth than for houses, meaning agriculture is assumed less vulnerable to surge than houses. It is also due to the much more homogenous distribution of agricultural lands in terms of value across the country relative to houses which are concentrated in certain zones. Like houses, surge impact on agriculture is mostly concentrated in the southern and northern regions; Mekong Delta and Red River Delta, respectively. Surge currently causes an AAL of $\$ 307$ million that increases to $\$ 410$ and 465 million in 2050 
under RCP4.5 and RCP8.5, respectively, assuming no change in TC frequency. In case of decreased TC frequency, there is a slight increase in AAL to \$325 million for RCP4.5 and remains at the current $\$ 307$ million for RCP8.5.

The number of people affected by surge has a similar spatial distribution to houses and agriculture damage from surge. There are however significantly more people affected by surge than by wind. Currently 1.94 million people are estimated to be impacted by storm surge along the coastline and in low-lying areas, increasing to 2.08 and 2.16 million people under RCP4.5 and RCP8.5, respectively, assuming no change in TC frequency. In the case of decreased TC frequency, the number of affected people decreases to 1.6 and 1.41 million for RCP 4.5 and RCP8.5, respectively. The damage to agriculture and housing along with number of affected people is considerably higher for surge (with most damage limited to coastal areas) than damage from wind (that affects inland areas as well) but due to lack of any observational dataset we can't compare these to any events in historical period. However this can be attributed and explained by the fact that the asset and people exposure is higher in coastal regions, Fig. 2 (with less value assets and populations distributed inland), secondly most of the Mekong delta region (that accounts for most of the surge damage) is topologically rather flat thus coastal water inundation could reach further inland (Fig. 4), and lastly the damage function, i.e. the probability of damage to certain event is higher for surge than wind (where category 1 ad 2 storms would have no to very low damage to assets) and they reach $100 \%$ impact rather sharply compared to wind damage functions (Fig. 3).

\subsection{Adaptation Measures and Cost-benefit Analysis}

Decision and policy makers need to understand potential weather and climate-related damages to be expected in the coming decades, and identify and evaluate measures to mitigate these risks ideally using evidence-based decision-making tools that assess the benefits versus the costs of such measures. CLIMADA provides such an economic framework that integrates risk and reward perspectives of different stakeholders (Bresch 2016). Figure 6 presents the quantified effects of the three considered adaptation measures by comparing the impact to each exposure class for each severity level of the wind and surge event (measured in probability of that event occurring or the return period) with and without the adaptation measures, the benefits from adaptation measures are treated separately and no cobenefits from three adaptation measures are considered herein. The results show that while climate change poses a major threat, the main amplifier across all scenarios is economic growth, which leads to higher exposure and higher impact estimates. Fortunately, the adaptation measures are able to decrease the impact of both wind and surge to a greater extent.

Figure 6 shows that across all exposures wind damage grows steadily as wind speed increases (higher return periods), whereas surge impact rises very rapidly before flattening out. This means that significant damage is caused by surge from relatively weak TCs which are linearly related to surge depth. For all scenarios, the adaptation measures reduce impact at all return periods; however, the measures are much more effective in reducing surge impact than wind especially in the case of agriculture. The same patterns can be observed when assuming the future climate scenario with decreased TC frequency.

The level of risk averted through specific adaptation measures was evaluated for events at three different levels of severity: 1 in 10-, 25-, and 100-year events. This benefit is net of the cost of implementing the measure, with results presented in Fig. 7A. 


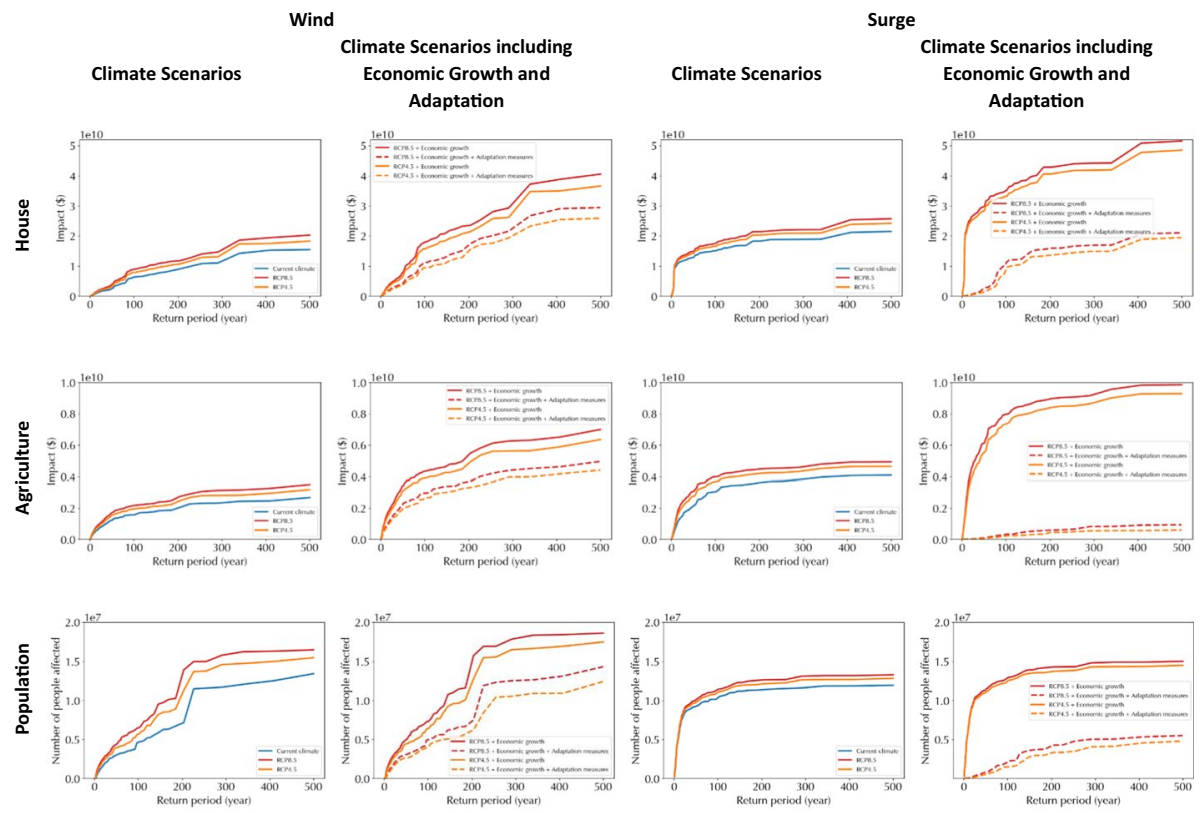

Fig. 6 Damage caused/number of people affected by wind and surge across each asset and for different severity levels (return period). The damage/number of people impacted is calculated under current and future 2050 climate scenarios (RCP4.5 and RCP8.5) assuming TC intensity increases with no change in TC frequency $(+\mathrm{I} / 0 \mathrm{~F})$. The impact of economic growth and adaptation measures are also modelled under both future climate scenarios assuming $(+\mathrm{I} / 0 \mathrm{~F})$

As outlined in Table 2, mangroves are the only adaptation measure that reduces wind impact and are supplemented by sea-dykes and gabions for reducing surge-related impacts and damages. The bar for each return period represents the estimated total damage from wind or surge for that particular type of event (1 in 10 year represents less severe, more frequent events while 1 in 100 years are much more severe and rare events). The coloured area of the bar represents the risk reduction benefit (less the cost) of the specific adaptation measure for that type of event. For the 1 in 10, 25 and 100year events, mangroves are estimated to provide around 50\% wind risk reduction considering the costs involved in planting and maintaining the mangrove forests for the foreseen periods. However, the combined system of mangroves, gabions and sea-dykes provides a comprehensive coverage of most and in some cases all surge risk, which is a substantial part of total damage. For agriculture, surge damage is completely averted by the three adaptation measures even for severe 1 in 100-year events. For houses, surge damage is totally averted for moderate 10 -year events, almost completely averted for more severe 1 in 25 -year events and reduced by a third for severe 1 in 100-year events. The measures reduce the number of people affected by surge by around $80 \%$ in both moderate 10 year and more severe 25 -year events and by around $70 \%$ for severe 100 year events. Residual risk is defined as the remainder of loss and damage that cannot be reduced through the combined system of physical adaptation measures. There are however a number of financing tools available to address this risk as discussed below. 
A
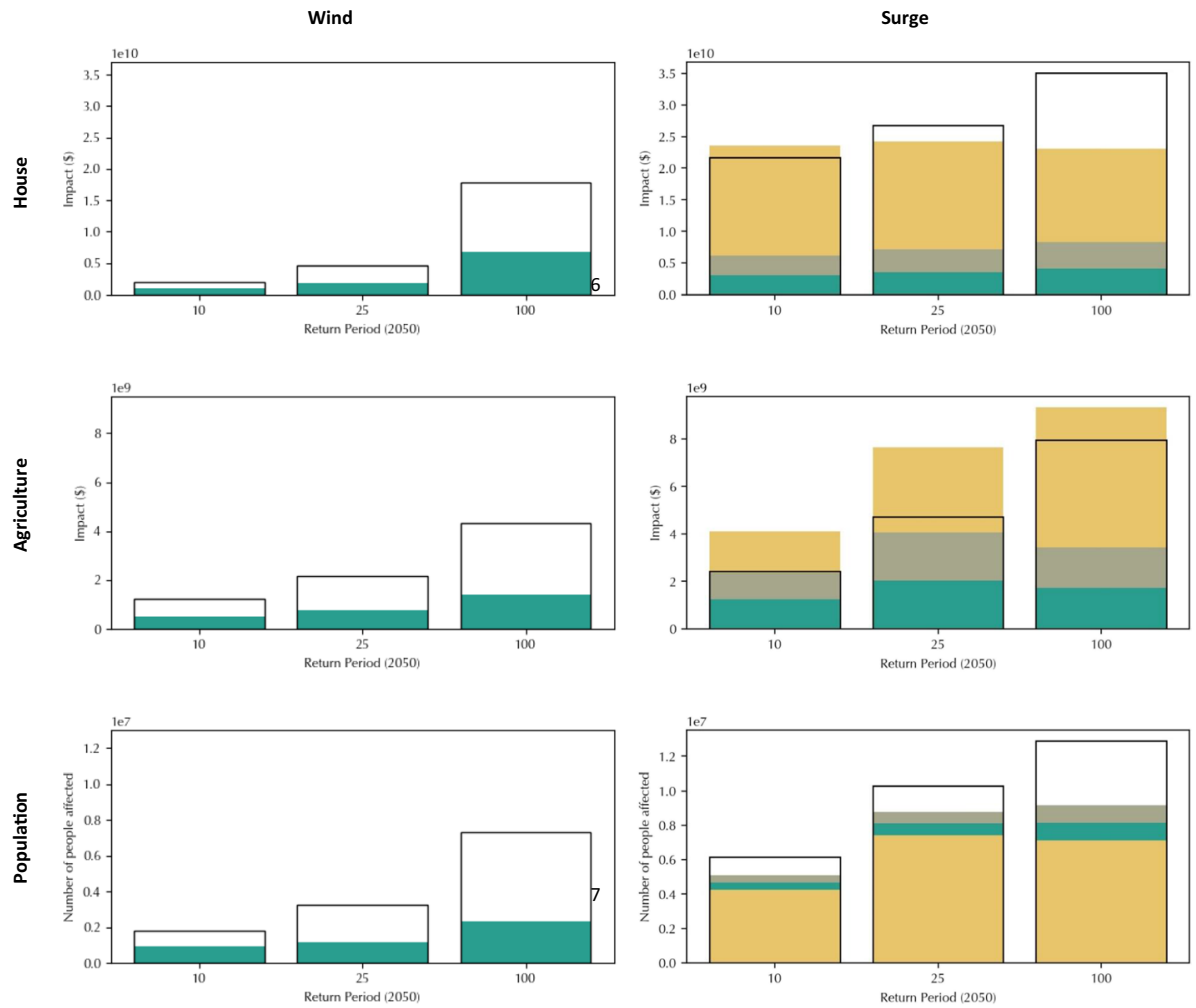

B

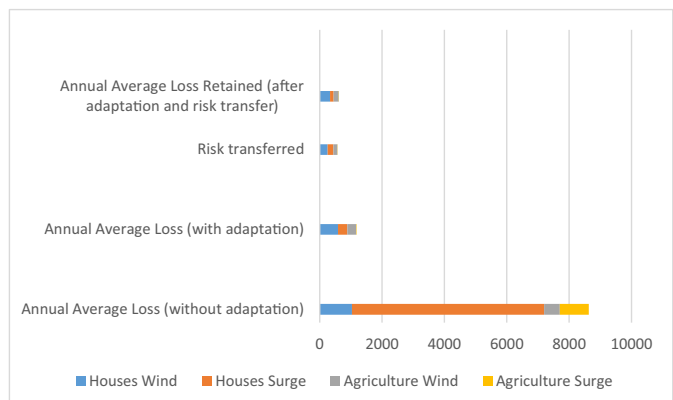

Fig. $7 \mathrm{~A}$ - Each bar represents the estimated total damage caused/number of people affected by wind/surge for the particular asset at three different severity levels (1 in 10 year; 1 in 25 year and 1 in 100-year events) as modelled in 2050 under climate scenario RCP8.5 assuming increased TC intensity and no change in frequency and taking in account economic growth. The coloured portion of the bar represents the reduction in damage/number of people affected due to an adaptation measure (Green: Mangroves; Grey: Gabions; Yellow: Sea-dykes) which are treated separately for benefits and no co-benefits from three adaptation measures are considered herein. This reduction in damage already takes into account the cost of putting the adaptation measure in place. B- Annual average loss for houses and agriculture (in \$ million) under future scenario RCP 8.5 assuming increased TC intensity and no change in frequency $(+\mathrm{I} / 0 \mathrm{~F})$ and taking into account economic growth without adaptation measures compared to the same scenario with adaptation measures in place. Insurance is applied to the residual risk remaining after adaptation measures: the AAL transferred is the portion of TC losses that insurers will bear on average every year. The AAL that remains after adaptation measures and risk transfer is the annual losses on average to be borne by the government, population and private sector 


\subsection{Risk transfer}

Viet Nam has adopted an increasingly proactive stance in managing disaster risk in recent years. The national government has made significant strides on disaster risk prevention and preparedness; along with response and reconstruction efforts. The national strategy identifies "proactive prevention" as a guiding principle to direct government's responsibility to anticipate, reduce, and prepare for potential disaster events and address needs of the people affected (Vietnam NDC 2020). This guides their underlined role and response to natural disasters. The current study provides a range of physical adaptation measures that can reduce the impact of those events on various assets; along with the likelihood and cost of future disaster events. The remaining risk, or residual risk, from a disaster shall be dealt in part through the government budget at the national and provincial level (ACT Alliance 2020). There are a variety of disaster risk financing tools available to address residual risk including risk transfer via insurance, which is most financially efficient in covering low frequency, high severity events.

The previous section analysed the benefits of physical adaptation measures focusing on events of three levels of severity of return periods 1, 25 and 100 years. Another perspective is to analyse the risk reduction benefit on an average annual basis (AznarSiguan and Bresch 2019). Figure 7B (also in tabular form in supplementary material Table 2) shows that incorporating the three adaptation measures reduces the AAL for storm surge risk across houses and agriculture by a significant $95-98 \%$ while that of wind risk reduces to a lesser extent by around $43 \%$. The remaining damage sustained on average per year (residual risk) is \$584 million for houses due to wind and \$299 million due to surge and $\$ 284$ million for agriculture due to wind and just $\$ 12,3$ million due to surge.

Insurance can be applied to this residual risk for houses with an attachment point (where the insurance starts paying) of 1 in 10-year loss and an exhaustion point (where the insurance stops paying) of 1 in 100 years loss. This means that the insurance would start paying once wind and surge damage to houses reached \$1024 million and \$255.9 million, respectively (10-year event) and would stop paying when damage reached a total of $\$ 11.11$ billion and $\$ 10.79$ billion, respectively (100-year event). The insurance coverage would be $\$ 10.1$ billion for wind damage and $\$ 10.5$ billion for surge damage.

The residual risk for agriculture could also benefit from risk transfer with insurance starting to pay when wind and surge damage reached \$387.9 million and \$4.398 million, respectively ( 1 in 5-year event) and stop paying when damage totalled \$2949 million and \$317.7 million (1 in 100-year event), respectively, for wind and surge. The insurance coverage for agriculture would be $\$ 2.6$ billion for wind damage and $\$ 0.3$ billion for surge damage.

These attachment and exhaustion points for the housing insurance cover were selected to align with similar TC sovereign insurance programmes in other countries (Cebotari and Youssef 2020) while the agriculture insurance attachment point was reduced to a 5 -year event to take into account the sector's higher sensitivity to TC risk. With such an insurance structure in place, around half of the residual risk would be transferred to insurers. The remaining risk would be at a level that is significantly more manageable by the national and provincial level governments than the original risk without adaptation measures nor insurance.

Reducing the risk as much as is financially efficient through adaptation measures allows insurance to be applied only to the residual risk which is critical in reducing the 
insurance costs to feasible levels. If no adaptation measures were put in place and insurance was applied to the larger original risk, the wind-caused AAL transferred to insurers would be $56.6 \%$ larger and the transferred damage of surge on agriculture would be more than 58 times larger which is considerable. As a result, the insurance costs would increase by the same order of magnitude compared to only transferring residual risk.

\section{Future Outlook}

Observational economic and displacement data due to TC events in the region is scarce, leading to a significant limitation in the current study with respect to model calibration for historical TC events. While EM-DAT and DesInventar do provide some observational data for historic events, the estimates are not comprehensive for the three selected asset classes. The authors refrained from modifying these observations on loss and people affected in order to compare them to CLIMADA output, as any assumptions used in the modifications would introduce uncertainty in the observational dataset. Thus there is increasing need of research in the direction wherein we could use event based observation to calibrate and compare the historical loss and damages to various asset categories from various natural hazards.

It would have been preferable to use a multi-hazard model representing TC hazard as a combination of wind, surge and rain-induced flood and landslide events as concluded from Eberenz et al. 2020 however, CLIMADA does not yet have modelling capabilities for raininduced flood and landslide. To note that the existing surge module used in the study did incorporate some advancements. Refined surge depths and in turn better impact assessment of surge damage was possible thanks to the improved CoastalDEM dataset used instead of SRTM3 data. Both datasets were analysed and it was found that the resolution was better resolved and represented in CoastalDEM for impact analysis of TCs.

Finally, the cost and benefits of the adaptation measures currently are taken from various published and unpublished literature, along with communications from experts in the region, and would vary from year to year and region to region. Thus a comprehensive evaluation of the cost-benefit would be possible in a localised study wherein the cost and benefits would be rather defined and would not be subjected to the sensitivity from geographical and temporal scales. Sensitivity analysis of cost and benefit of these adaptation measures would provide an interesting insight and should be studied in detail for better understanding of the issue.

\section{Conclusion}

The creation of an economic framework for policy and decision makers to understand the benefits in risk reduction and costs involved in developing adaptation strategies is key to addressing climate risk. In this paper, the impact of TC wind and surge risk was evaluated across Viet Nam focusing on three key assets-houses, agriculture, and people-in current and future scenarios which incorporate economic growth and various climate change scenarios. Wind and surge risk was shown to significantly increase under most of the future scenarios.

The impact functions used in the study were adopted from previous research in the field and region. Wind impact estimates are spatially concentrated in larger population centres 
across the country and face incremental damage in future scenarios. Surge impact is most concentrated in the Mekong and Red River Deltas and causes damage that is four times greater than wind damage for all scenarios. Based on the authors' observations, it is recommended to consider spatial differences in vulnerability for the specific asset and implement an adaptation and resilience strategy accordingly.

Physical adaptation measures-mangroves, gabions and sea-dykes-were presented that could avert the economic and social impacts of TCs. These measures were applied to the TC wind and surge risk estimated for future scenarios. It is very evident that the adaptation measures presented substantially reduce risk/impact to the assets and are very cost efficient especially against damage due to surges, where future average annual loss of houses and agriculture is reduced by $95.2 \%$ and $98.6 \%$, respectively. Although the adaptation measures are able to reduce significant amounts of the wind and surge risk, there is still residual risk remaining especially for very severe events. A risk transfer solution through insurance was presented that would allow this residual risk to be halved on average. However, adaptation measures were seen as critical in order to keep insurance costs at feasible levels.

In terms of future research, observational data limitations of the current study demand further analysis in order to have a reasonable comparison to the model output. There is equally a need for multi-hazard analysis using CLIMADA. Improvements in DEM are notable and have helped in improving the analysis of surge in this data-scarce region.

Supplementary Information The online version contains supplementary material available at https:/doi. org/10.1007/s10584-021-03290-y.

Acknowledgement We would like to acknowledge various data providers for producing and making available their observational/model data. This study was kindly funded by the KfW German Development Bank on behalf of the German Federal Ministry for Economic Cooperation and Development (BMZ).

Funding Open Access funding enabled and organized by Projekt DEAL. This study was kindly funded by the KfW German Development Bank on behalf of the German Federal Ministry for Economic Cooperation and Development (BMZ)

Data availability Processed data can be made available on request

Code availability Codes would be made available via Github repository on the following link on request https://github.com/arunranain/climada_tc_vietnam

\section{Declarations}

Conflict of Interest/Competing interests No known conflict of interest to the authors

Open Access This article is licensed under a Creative Commons Attribution 4.0 International License, which permits use, sharing, adaptation, distribution and reproduction in any medium or format, as long as you give appropriate credit to the original author(s) and the source, provide a link to the Creative Commons licence, and indicate if changes were made. The images or other third party material in this article are included in the article's Creative Commons licence, unless indicated otherwise in a credit line to the material. If material is not included in the article's Creative Commons licence and your intended use is not permitted by statutory regulation or exceeds the permitted use, you will need to obtain permission directly from the copyright holder. To view a copy of this licence, visit http://creativecommons.org/licenses/by/4.0/. 


\section{References}

ACT Alliance (2020) Climate Risk Insurance and Risk Financing in the Context of Climate Justice: A Manual for Development and Humanitarian Aid Practitioners. https://reliefweb.int/sites/reliefweb.int/files/ resources/Climate-Risk-Insurance-Manual_English-1.pdf Accessed 3 November 2021

Anh LT, Takagi H, Thao ND (2019) Storm Surge and High Waves Due to 1997 Typhoon Linda: Uninvestigated Worst Storm Event in Southern Vietnam. Journal of Japan Society of Civil Engineers. Ser. B3 (Ocean Engineering) 75(2):73-78

Aon (2019) Weather, Climate \& Catastrophe Insight: 2019 Annual Report. http://thoughtleadership.aon. com/Documents/20200122-if-natcat2020.pdf?utm_source=ceros\&utm_medium=storypage\&utm_ campaign=natcat20. Accessed 21 September 2020

Arouri M, Nguyen C, Youssef AB (2015) Natural Disasters, Household Welfare, and Resilience: Evidence from Rural Vietnam. World Development 70:59-77 ISSN 0305-750X. https://doi.org/10.1016/j.world dev.2014.12.017

Aznar-Siguan G, Bresch DN (2019) CLIMADA v1: a global weather and climate risk assessment platform. Geosci Model Dev 12:3085-3097. https://doi.org/10.5194/gmd-12-3085-2019

Bakkensen LA, Mendelsohn RO (2016) Risk and Adaptation: Evidence from Global Hurricane Damages and Fatalities. J Assoc Environ Res Econ 3:555-587. https://doi.org/10.1086/685908

Braese J et al. (2020) Coastal Development between Opportunity and Disaster Risk: A Multisectoral Risk Assessment for Vietnam. Policy Research Working Paper 9352 World Bank Washington, DC. https://doi.org/10.1596/1813-9450-9352

Bresch DN (2016) Shaping Climate Resilient Development - Economics of Climate Adaptation. In: Salzmann G, Huggel N, Nussbaumer C, and Ziervogel SU (ed) Climate Change Adaptation Strategies - An Upstream-downstream Perspective. Springer. https://link.springer.com/book/10.1007\% 2F978-3-319-40773-9.

Bresch DN, Aznar-Siguan G (2020) CLIMADA v1.4.1: Towards a Globally Consistent Adaptation Options Appraisal Tool. Geoscientific Model Development Discussions 7:1-20. https://doi.org/10. 5194/gmd-2020-151

Bruyère CL et al (2019) Physically-Based Landfalling Tropical Cyclone Scenarios in Support of Risk Assessment. Weather and Climate Extremes 26. https://doi.org/10.1016/j.wace.2019.100229

Cebotari A and Youssef K (2020) Natural Disaster Insurance for Sovereigns: Issues, Challenges and Optimality. IMF Working Papers 20. https://doi.org/10.5089/9781513525891.001.

Chausson A, Turner B, Seddon D et al (2020) (2020) Mapping the effectiveness of Nature-based Solutions for climate change adaptation. Glob Change Biol. 26:6134-6155. https://doi.org/10.1111/gcb. 15310

Cheong SM, Silliman B, Wong PP, van Wesenbeeck B, Kim CK, Guannel G (2013) Coastal adaptation with ecological engineering. Nat Clim Chang Nature Publishing Group 3:787-791

Choi W, Ho CH, Kim J et al (2019) Near-future tropical cyclone predictions in the western North Pacific: fewer tropical storms but more typhoons. Clim Dyn 53:1341-1356. https://doi.org/10.1007/ s00382-019-04647-x

Collins M, Sutherland M, Bouwer L, Cheong SM, Frölicher T, Jacot Des Combes H, Koll Roxy M, Losada I, McInnes K, Ratter B, Rivera-Arriaga E, Susanto RD, Swingedouw D, Tibig L (2019) Extremes, Abrupt Changes and Managing Risk. In: Pörtner HO, Roberts DC, Masson-Delmotte V, Zhai P, Tignor M, Poloczanska E, Mintenbeck K, Alegría A, Nicolai M, Okem A, Petzold J, Rama B, Weyer NM (eds) IPCC Special Report on the Ocean and Cryosphere in a Changing Climate. In press

Cooper JAG, Pile J (2014) The adaptation-resistance spectrum: A classification of contemporary adaptation approaches to climate-related coastal change. Ocean Coast Manag 94:90-98. https://doi.org/ 10.1016/j.ocecoaman.2013.09.006

Eberenz S, Stocker D, Röösli T, Bresch DN (2020) Asset exposure data for global physical risk assessment. Earth Syst Sci Data 12:817-833. https://doi.org/10.5194/essd-12-817-2020

EM-Database (2020) EM-DAT, CRED / UCLouvain, Brussels, Belgium - www.emdat.be (D. GuhaSapir), https://public.emdat.be/ Accessed 21 September 2020

Geiger T, Frieler K, Levermann A (2016) High-income does not protect against hurricane losses. Environ Res Lett 11:084012. https://doi.org/10.1088/1748-9326/11/8/084012

Geiger T, Frieler K, Levermann A (2017) High-income does not protect against hurricane losses. Environ Res Lett 12:098002. https://doi.org/10.1088/1748-9326/AA88D6

Geiger T, Frieler K, Bresch DN (2018) A global historical data set of tropical cyclone exposure (TCEDAT). Earth Syst Sci Data 10:185-194. https://doi.org/10.5194/essd-10-185-2018

GOV (2009) National Programme on Community Based Disaster Risk Management (CBDRM), https:// www.ifrc.org/docs/idrl/916EN.pdf. Accessed 21 September 2020 
GOV (2011) National Strategy on Climate Change, http://www.chinhphu.vn/portal/page/portal/English/ strategies/strategiesdetails?categoryId=30\&articleId=10051283) Accessed 21 September 2020

GOV (2016) Socio-economic Development Plan (SEDP) 2016-2020, http://www.chinhphu.vn/portal/ page/portal/English/strategies/strategiesdetails?categoryId=30\&articleId=10057712) Accessed 21 September 2020

Guan S, Li S, Hou Y, Hu P, Liu Z, Feng J (2018) Increasing threat of landfalling typhoons in the western North Pacific between 1974 and 2013. Int J Appl Earth Observ Geoinformation 68:279-286 ISSN 0303-2434. https://doi.org/10.1016/j.jag.2017.12.017

Guha-Sapir D (2017) EM-DAT: The Emergency Events Database - Université catholique de Louvain (UCL) - CRED. Brussels, Belgium. available at: www.emdat.be. Accessed 21 September 2020

Hallegatte S, Green C, Nicholls RJ, Corfee-Morlot J (2013) Future flood losses in major coastal cities. Nat Clim Chang Nature Publishing Group 3:802-806

Holland G (2008) A Revised Hurricane Pressure-Wind Model. Monthly Weather Rev 136(9):34323445. https://doi.org/10.1175/2008MWR2395.1

Holland GJ, Bruyère CL (2014) Recent intense hurricane response to global climate change. Clim Dynam 42:617-627. https://doi.org/10.1007/s00382-013-1713-0

Huizinga J, de Moel H, Szewczyk W (2017) Global flood depth-damage functions. Methodology and the database with guidelines. EUR $28552 \mathrm{EN}$. https://doi.org/10.2760/16510

IMHEM and UNDP (2015) Viet Nam Special Report on Managing the Risks of Extreme Events and Disasters to Advance Climate Change Adaptation, Viet Nam Publishing House of National Resources, Environment and Cartography Ha Noi, Vietnam: 249 ff. https://www.vn.undp.org/content/vietnam/en/home/libra ry/environment_climate/viet_nam_special_report_on_managing_the_risks_of_extreme_events_and_disas ters.html. Accessed 21 September 2020

JRC (2020) INFORM Risk - Inform risk index, European commission. https://drmkc.jrc.ec.europa.eu/informindex/INFORM-Risk. Accessed 21 September 2020

James R, Otto F, Parker H, Boyd E, Cornforth R, Mitchell D et al (2014) Characterizing loss and damage from climate change. Nat Clim Chang Nature Publishing Group 4:938-939. https://doi.org/10.1038/nclimate24 11

Jones B, O’Neill BC (2016) Spatially explicit global population scenarios consistent with the Shared Socioeconomic Pathways. Environ Res Lett 11:084003. https://doi.org/10.1088/1748-9326/11/8/084003

Jongman B, Ward PJ, Aerts JCJH (2012) Global exposure to river and coastal flooding: Long term trends and changes. Glob Environ Chang. Elsevier Ltd 22:823-835

Kefi M, Mishra BK, Kumar P, Masago Y, Fukushi K (2018) Assessment of Tangible Direct Flood Damage Using a Spatial Analysis Approach under the Effects of Climate Change: Case Study in an Urban Watershed in Hanoi, Vietnam. ISPRS International Journal of Geo-Information 7(1):1-18

Knapp K, Kruk MC, Levinson DH, Diamond HJ, Neumann CJ (2010) The International Best Track Archive for Climate Stewardship (IBTrACS). B Am Meteorol Soc 91:363-376. https://doi.org/10.1175/2009BAMS27 55.1

Knutson TR, Sirutis JJ, Zhao M, Tuleya RE, Bender M, Vecchi GA, Villarini G, Chavas D (2015) Global Projections of Intense Tropical Cyclone Activity for the Late Twenty-First Century from Dynamical Downscaling of CMIP5/RCP4.5 Scenarios. J Climate 28 18:7203-7224

Knutson T et al (2019) Tropical Cyclones and Climate Change Assessment: Part I: Detection and Attribution. Bull Amer Meteor Soc 100:1987-2007. https://doi.org/10.1175/BAMS-D-18-0189.1

Knutson T et al (2020) Tropical Cyclones and Climate Change Assessment: Part II: Projected Response to Anthropogenic Warming. Bull Amer Meteor Soc 101:E303-E322. https://doi.org/10.1175/ BAMS-D-18-0194.1

Kuhn M and Ríos-Rull JV (2016) 2013 Update on the U.S. Earnings, Income, and Wealth distributional Facts: A View from Macroeconomics. Quarterly Rev 37 https://doi.org/10.21034/qr.3711

Kulp SA, Strauss BH (2018) CoastalDEM: A global coastal digital elevation model improved from SRTM using a neural network. Remote Sensing of Environment 206:231-239. https://doi.org/10.1016/J.RSE. 2017.12.026

Kulp SA, Strauss BH (2019) New elevation data triple estimates of global vulnerability to sea-level rise and coastal flooding. Nat Commun 10:4844. https://doi.org/10.1038/s41467-019-12808-Z

Kumano N, Tamura M, Inoue T, Yokoki H (2021) Estimating the cost of coastal adaptation using mangrove forests against sea level rise. Coastal Eng J 63(3):263-274. https://doi.org/10.1080/21664250.2021.1892968

Lap TQ (2019) Researching the Variation of Typhoon Intensities Under Climate Change in Vietnam: A Case Study of Typhoon Lekima, 2007. Hydrology 6(2):51. https://doi.org/10.3390/hydrology6020051

Lien M (2019) Vulnerability Assessment of Climate Change on Sea Level Rise Impacts on Some Economic Sectors in Binh Dinh Province, Vietnam. Am J Climate Change 8:302-324. https://doi.org/10.4236/ajcc. 2019.82017 
Mason M, and Parackal K (2015) Vulnerability of buildings and civil infrastructure to tropical cyclones: A preliminary review of modelling approaches and literature. Bushfire and Natural Hazards. available at: https:// www.bnhcrc.com.au/sites/default/files/managed/downloads/vulnerability_of_buildings_and_civil_infrastructure_to_tropical_cyclones.pdf. Accessed 21 September 2020

National Statistics Bureau (2010) Gross output of agriculture at constant 1994 prices by province. Available at https://www.gso.gov.vn/default.aspx?tabid=387\&idmid=3\&ItemID=13078 Accessed 21 September 2020

Nhu YN, Yutaka I, Hiroshi I (2017) Establishing flood damage functions for agricultural crops using estimated inundation depth and flood disaster statistics in data-scarce regions. Hydrol Res Lett. https://doi.org/10. 3178/hrl.11.12 https://www.jstage.jst.go.jp/article/hrl/11/1/11_12/_article/-char/en

Oliphant AJ, Thenkabail PS, Teluguntla P, Xiong J, Congalton RG, Yadav K, Massey R, Gumma MK, Smith C (2017) NASA Making Earth System Data Records for Use in Research Environments (MEaSUREs) Global Food Security-support Analysis Data (GFSAD) Cropland Extent 2015 Southeast Asia $30 \mathrm{~m}$ V001. 2017. distributed by NASA EOSDIS Land Processes DAAC. https://doi.org/10.5067/MEaSUREs/ GFSAD/GFSAD30SEACE.001. Accessed 21 September 2020

Oppenheimer M, Glavovic BC, Hinkel J, van de Wal R, Magnan AK, Abd-Elgawad A, Cai R, CifuentesJara M, DeConto RM, Ghosh T, Hay J, Isla F, Marzeion B, Meyssignac B, and Sebesvari Z (2019) Sea Level Rise and Implications for Low-Lying Islands, Coasts and Communities. In: Pörtner HO, Roberts DC, MassonDelmotte V, Zhai P, Tignor M, Poloczanska E, Mintenbeck K, Alegría A, Nicolai M, Okem A, Petzold J, Rama B, Weyer NM (eds.) IPCC Special Report on the Ocean and Cryosphere in a Changing Climate. In press

Peduzzi P, Chatenoux B, Dao H, De Bono A, Herold C, Kossin J et al (2012) Global trends in tropical cyclone risk. Nat Clim Chang Nature Publishing Group 2:289-294

Pham NT, Nguyen QH, Ngo AD et al (2018) Investigating the impacts of typhoon-induced floods on the agriculture in the central region of Vietnam by using hydrological models and satellite data. Nat Hazards 92:189-204. https://doi.org/10.1007/s11069-018-3202-6

Spalding MD, Mcivor AL, Beck MW, Koch EW, Möller I, Reed DJ et al (2014) Coastal ecosystems: A critical element of risk reduction. Conserv Lett 7:293-301

Takagi H (2019) Statistics on typhoon landfalls in Vietnam: Can recent increases in economic damage be attributed to storm trends? Urban Climate 30100506 ISSN 2212-0955 https://doi.org/10.1016/j.uclim.2019. 100506.

Tamura M, Kumano N, Yotsukuri M et al (2019) Global assessment of the effectiveness of adaptation in coastal areas based on RCP/SSP scenarios. Climatic Change 152:363-377. https://doi.org/10.1007/ s10584-018-2356-2

Temmerman S, Meire P, Bouma TJ, Herman PMJ, Ysebaert T, De Vriend HJ et al (2013) Ecosystem-based coastal defence in the face of global change. Nature 504:79-83

Thuy HLT, Co NT, Hang PTT, Tuan TP (2015) Characteristics of typhoon activity in the coastal area of North center Region, Vietnam in the period 1960-2013. Vietnam J Earth Sci 37(3):222-227

Thuy NB (2019) The risk of typhoon and storm surge along the coast of Vietnam. Vietnam J Marine Sci Technol 19(3):327-336

UNISDR: Making Development Sustainable (2015) The Future of Disaster Risk Management, Global Assessment Report on Disaster Risk Reduction. United Nations Office for Disaster Risk Reduction (UNISDR), Geneva

UNFCCC: Intended Nationally Determined Contribution of Viet Nam (2011) Available at https://www4.unfccc. int/sites/ndcstaging/PublishedDocuments/Viet\%20Nam\%20First/VIETNAM'S\%20INDC.pdf Accessed 19 October 2021

United Nations, Department of Economic and Social Affairs, Population Division (2019) World Population Prospects 2019, Online Edition. Rev. 1. available at https://population.un.org/wpp/Download/Standard/ Population/ Accessed 21 September 2020

Van Ledden M et al (2020) Coastal development between opportunity and disaster risk: An assessment of the coastal protection system in Vietnam. Policy Research Working Paper 9351. World Bank, Washington, DC. https://doi.org/10.1596/1813-9450-9351

Vietnam Updated Nationally Determined Contribution (2020) https://www4.unfccc.int/sites/ndcstaging/PublishedDocuments/Viet\%20Nam\%20First/Viet\%20Nam_NDC_2020_Eng.pdf. Accessed 3 November 2021

Villarini G, Vecchi GA (2013) Projected increases in North Atlantic tropical cyclone intensity from CMIP5 models. J Climate 26:3231-3240. https://doi.org/10.1175/JCLI-D-12-00441.1

Vu DT, Yamada T, Ishidaira H (2018) Assessing the impact of sea level rise due to climate change on seawater intrusion in Mekong Delta, Vietnam. Water Sci Technol. 77(5-6):1632-1639. https://doi.org/10.2166/wst. 2018.038

World Bank (2010) Vietnam: Economics of Adaptation to Climate Change. Washington, DC. 
World Bank (2016) Transforming Vietnamese Agriculture: Gaining More from Less. Vietnam Development Report. World Bank, Washington, D.C

World Bank (2020a) World Bank DataBank. https://data.worldbank.org/indicator/NY.GNP.PCAP.CD?locat ions $=$ VN\&view $=$ chart Accessed 21 September 2020

World Bank (2020b) World Bank Country Classification. https://datahelpdesk.worldbank.org/knowledgebase/ articles/906519-world-bank-country-and-lending-groups Accessed 21 September 2020

World Development Indicators (2020) Inflation, consumer prices (annual \%). https://databank.worldbank.org/ reports.aspx? source=world-development-indicators\# Accessed 21 September 2020

Xu L (2010) A Simple Coastline Storm Surge Model Based on Pre-Run SLOSH Outputs. 8. 2010. https://ams. confex.com/ams/pdfpapers/168806.pdf.

Publisher's note Springer Nature remains neutral with regard to jurisdictional claims in published maps and institutional affiliations. 